\title{
RESIDÊNCIA NAS ESCOLAS AGRÍCOLAS DE ENSINO TÉCNICO: ALTERNATIVA PARA A EDUCAÇÃO PROFISSIONAL PÚBLICA NO ESTADO DE SÃO PAULO
}

\author{
RESIDENCIA EN LAS ESCUELAS AGRÍCOLAS TÉCNICAS: ALTERNATIVA \\ PARA LA FORMACIÓN PROFESIONAL PÚBLICO EN EL ESTADO DE SÃO \\ PAULO
}

INTERNSHIP IN AGRICULTURAL SCHOOLS: AN ALTERNATIVE FOR PUBLIC VOCATIONAL EDUCATION IN STATE OF SÃO PAULO

\author{
Paulo CONSTANTINO ${ }^{1}$ \\ Marcia POLETINE ${ }^{2}$ \\ Antonio Carlos Ottoboni de OLIVEIRA ${ }^{3}$
}

RESUMO: Analisa a manutenção do sistema de residência escolar para o ensino técnico agrícola no Estado de São Paulo, Brasil, a partir da experiência de uma instituição pública de educação profissional, por meio de pesquisa híbrida realizada em 2014 e 2015. Residências escolares oferecem ao aluno a oportunidade de obter sua formação de modo intensivo, durante um período de tempo específico, dentro de uma escola agrícola. Neste formato, a expectativa é que os estudantes possam adquirir experiência, obter sua formação geral e uma perspectiva mais aprofundada sobre a profissão que escolheram, que os ajudará nas decisões de manutenção da carreira ou no aprofundamento dos estudos, cumprindo a perspectiva politécnica e multifacetada almejada para esta modalidade de ensino.

PALAVRAS-CHAVE: Residência escolar. Ensino técnico. Ensino agrícola.

RESUMEN: Se analiza el mantenimiento del sistema de residencia escolar para la educación agrícola en el provincia de São Paulo, Brasil, a partir de la experiencia de una institución pública de educación profesional através de investigacion realizado en 2014 y 2015. Las residencias escolares ofrecen a la estudiante la oportunidad de entrenamiento intensivo para un período específico de tiempo dentro de una escuela agrícola. En este formato, la expectativa es que los estudiantes puedan adquirir experiencia, obtener su educación general y más perspectiva sobre la profesión que han elegido, lo que ayudará en la carrera de las decisiones de mantenimiento o para profundizar en el estudio, el cumplimiento de la politécnica y la perspectiva multifacética deseada para este tipo de educación.

\footnotetext{
${ }^{1}$ Doutor em Educação pela UNESP Marília. Atua na supervisão escolar das escolas técnicas estaduais de São Paulo, na região de Marília/SP e como professor na UNESP Marília. E-mail: pconst2@ gmail.com.br ${ }^{2}$ Atua na supervisão escolar das escolas técnicas estaduais de São Paulo, na região de Marília/SP. E-mail: mpoletine@gmail.com

3 Atua na coordenação de projetos junto às escolas técnicas agrícolas do Estado de São Paulo. E-mal: ottoboni_ac@hotmail.com
} 
PALAVRAS CLAVE: Residencia escolares. Educación técnica. Educación agrícola.

ABSTRACT: Analyzes the maintenance of the internship system for agricultural vocational education in the State of São Paulo, from the experience of a public institution, through hybrid survey conducted between 2014 and 2015. Internships offer students the opportunity to obtain their training intensely during a specific period of time within a agricultural school. In this format, the expectation is that students can acquire experience and a more accurate perspective on the profession they have chosen, which will help in the career of maintenance decisions or to deepen the studies, fulfilling the polytechnic and multifaceted perspective.

KEYWORDS: Internship. Vocational Education. Agricultural Education.

\section{Introdução}

Este artigo analisa a manutenção do sistema de residência escolar para o ensino técnico agrícola no Estado de São Paulo, Brasil, a partir da experiência verificada em uma instituição pública de educação profissional, o Centro Paula Souza. No início de 2015, 6230 alunos (CETEC, 2015) estavam matriculados apenas nos cursos comumente caracterizados como agrícolas, o que demonstra a amplitude deste atendimento.

Tal modelo de residência escolar, distanciando-se dos antigos internatos agrícolas, oferece aos alunos a oportunidade de aprender de modo intensivo, durante um período de tempo específico, em uma escola técnica associada ao campo, conforme descreveremos mais adiante. Neste formato, a expectativa é que os estudantes possam adquirir experiências e obter uma perspectiva mais aprofundada sobre a profissão que escolheram, que lhes ajudará nas decisões de manutenção da carreira ou no aprofundamento dos estudos, cumprindo a perspectiva politécnica e multifacetada desejada para esta modalidade de ensino, seja integrado, concomitante ou subsequente ao ensino médio brasileiro.

Se de fato tornou-se "urgente repensar a atual proposta de formação técnica bem como as atuais práticas educativas das escolas agrotécnicas" (SOBRAL, 2009, p.94), o sistema de residência nas escolas técnicas agrícolas do Centro Paula Souza pode ser uma alternativa viável para tal empreita. Ao apoiar a residência como uma iniciativa importante para a educação em tempo integral, confirma-se a constatação de que, no momento presente da escola brasileira, o tempo de permanência dos alunos na 
escola "está muito aquém do que seria necessário para dar conta da formação de nossas crianças e jovens para os desafios do século XXI” (GUARÁ, 2006, p.18).

Existem estudos que tratam, por exemplo, das expectativas paternas sobre o uso de internatos, como os de Silva e Rabinovich (2007); as experiências de internato de curta duração (RUIZ et al., 1985); o histórico do ensino técnico agrícola (SOBRAL, 2009) ou os aspectos fundamentais da educação no campo (THERRIEN E DAMASCENO, 1993). Tais obras nos serviram de referência para a construção deste artigo. Não abordaremos a residência como um espaço de internato total (GOFFMAN, 1974), por não se tratar da experiência dos alunos que ali estão. Também não nos deteremos nos elementos ou expectativas das famílias de origem para a escolha da instituição, como "ideais de vida, compensação, substituição da família, fator de crescimento ou de punição para os filhos" (SILVA e RABINOVICH, 2007, p.70).

As considerações desta pesquisa detêm-se ao desenvolvimento acadêmico possível no contexto do ensino técnico agrícola, retomando brevemente aspectos históricos desta modalidade no Brasil, para passar à reflexão sobre a residência escolar na educação profissional e o levantamento e análise das condições atuais de oferta dentro da instituição pública objeto da investigação.

\section{Metodologia e caracterização}

Para esta abordagem, adotou-se uma perspectiva híbrida de pesquisa. Em um primeiro momento, configurou-se uma pesquisa documental nos moldes apresentados por Tozoni-Reis (2010), pelo fato da investigação ter como fonte primordial os documentos oficiais da instituição focada. Isto significou "que a busca de informações sobre os fenômenos investigados foi realizada nos documentos que exigiam, para a produção de conhecimentos, uma análise" (TOZONI-REIS, 2010, p. 141). Em um segundo momento, por meio do instrumental da pesquisa de campo (TOZONI-REIS, 2010, p.142), com o uso de questionários semiestruturados, analisou-se o grupo focal de 34 escolas agrícolas, dentre as 218 escolas técnicas que compõem a instituição.

Seu desenvolvimento deu-se durante um tempo relativamente curto, entre o segundo semestre de 2014 e o primeiro de 2015, para que, baseado nos documentos e na literatura disponível, se estabelecesse um conjunto de reflexões sistematizadas e 
expostas no presente artigo, bem como servir aos propósitos internos de supervisão educacional e gestão de recursos das unidades da instituição.

Quanto à caracterização da instituição pesquisada, o Centro Estadual de Educação Tecnológica Paula Souza, ou Centro Paula Souza, informa-se que iniciou suas atividades em 06 de outubro de 1969, como uma entidade autárquica destinada a articular e desenvolver a educação técnica e tecnológica de nível médio e superior no Estado de São Paulo. Atualmente ligada à Secretaria do Desenvolvimento Econômico, Ciência, Tecnologia e Inovação, mantém 218 Escolas Técnicas [Etecs] e 64 Faculdades de Tecnologia [Fatecs] em funcionamento em mais de 300 municípios do Estado (CETEC, 2015). Somente no Ensino Médio e Técnico, em setores e eixos tecnológicos diversificados entre serviços, indústria, saúde e a produção cultural, o número de alunos matriculados ultrapassou 212 mil em diferentes habilitações no primeiro semestre de 2015, conforme informação da Unidade de Ensino Médio e Técnico da instituição em sua página oficial (CETEC, 2015).

Distribuídas por todo o Estado de São Paulo, 34 das 218 escolas técnicas são consideradas agrícolas. Estas unidades ofertam não somente os cursos do Eixo Tecnológico de Recursos Naturais, mas também outras habilitações ligadas aos diversos eixos previstos no Catálogo Nacional de Cursos Técnicos (MEC, 2012). No primeiro semestre de 2015, mais de 18.000 matrículas foram realizadas nestas 34 Etecs 'agrícolas', 6230 considerando-se apenas nos seguintes cursos do eixo tecnológico Técnico em Agricultura, Agroecologia, Agropecuária, Agronegócio, Cafeicultura, Florestas, Mecanização Agrícola e Zootecnia, nas modalidades integradas, concomitantes ou subsequentes ao ensino médio (CETEC, 2015).

Algumas características são fundamentais para reconhecer estas 34 escolas agrícolas, tais como: possuir uma fazenda-escola, de tamanho variável; serem unidades que precisam de manutenção perene dos espaços físicos e locais de funcionamentos dos projetos produtivos, mesmo em períodos de recesso escolar; possuir máquinas, equipamentos e implementos agrícolas com finalidades de aprendizagem, que requerem o domínio de métodos e procedimentos adequados de manuseio, a fim de garantir a segurança dos alunos e professores envolvidos nas atividades pedagógicas; realizar parcerias com uma Cooperativa-Escola, empresa organizada e reconhecida sob o ponto de vista jurídico e financeiro, com fins pedagógicos; e contar com alojamentos para alunos residentes em regime integral ou parcial, oriundos de outros municípios e estados, variando atualmente de 08 até 240 residentes em algumas Etecs. 
O próprio sistema de fazenda-escola "apresenta particularidades e peculiaridades que permitem pensar e desenvolver o trabalho como princípio educativo, aproximando a metodologia de ensino aos princípios da politecnia" (SOBRAL, 2009, p.94), fazendo com que a residência escolar seja um mecanismo adequado à proposta educacional integral almejada pela instituição. Passaremos a analisá-la no próximo momento.

\section{Resultados obtidos}

Os jesuítas, dentre outros religiosos que desembarcaram no Brasil na segunda metade do século XVI, foram os pioneiros a tratar da educação rural na então colônia portuguesa. Suas práticas normalmente baseavam-se em regimes de internato, em voga no Velho Continente, organizando núcleos escolares que ensinavam - além da doutrina - a lavrar a terra e outros pequenos ofícios. Este incipiente ensino agrícola, ministrado por ordens religiosas e padres jesuítas, era voltado principalmente aos filhos de colonos e aos povos indígenas, com o objetivo de organizar a exploração das fazendas de propriedade dos primeiros e manter uma agropecuária de sustentação básica. (SOBRAL, 2005, p. 12).

Os termos internato e residência, portanto, estão embebidos em significados construídos historicamente ao longo dos últimos séculos. A condição comum entre eles seria o residir do aluno na própria escola onde se estuda ou estagia, nos casos das abordagens mais recentes. Nos internatos particulares, por exemplo, criados para atender aos filhos das pessoas de alto poder aquisitivo, o objetivo era manter uma elite educacional e preservar seu status quo (PARO, 1988). Nos internatos públicos, a marca assistencialista (SOARES; TAVARES, 1999) predominou historicamente.

Conforme identificado por Pologeorgis (2012), residências escolares têm sido usadas como um rito de passagem para adolescentes e jovens. Seu conceito envolve uma abordagem que remonta à figura dos aprendizes de ofício, e se refere essencialmente ao treinamento e ao aprendizado em situações práticas, oferecendo ao aluno-aprendiz a oportunidade de envolver-se em seu trabalho de modo intensivo, durante um período de tempo específico. Este aparato da residência no ensino técnico agrícola, 
[...] além de ser necessário para o funcionamento do sistema escolafazenda, na medida em que apresenta inúmeras atividades fora do horário convencional de aulas, busca, ao mesmo tempo, possibilitar ao aluno compreender o sentido de coletividade que dificilmente conseguiria em escolas com outras características. A produção agrícola realizada na escola-fazenda é, pois fruto do trabalho coletivo da cooperação (MEC - SETEC, 2009, p.18).

Baseados nestas ideias de Pologeorgis (2012), entendeu-se que a residência nas escolas agrícolas da instituição poderia ser orientada por algumas diretrizes gerais:

- A experiência na residência escolar deve beneficiar diretamente o residente, em primeiro lugar, seguindo-se a escola e a comunidade;

- A residência enfatiza os aspectos procedimentais e de formação profissional, por isso, caracteriza-se como um ambiente educacional;

- O aluno interno não será um 'empregado' da instituição ou da cooperativa, mas terá a oportunidade de trabalhar sob a supervisão de uma equipe pedagógica e gestora;

- Todas as unidades escolares possuem autonomia para constituir um Conselho de Residência, de caráter deliberativo.

Constituído em 100\% das 34 escolas técnicas agrícolas, o sistema de residência do Centro Paula Souza não corresponde à “instituição total” de Goffman (1974, p. 16), pois permite a circulação livre dos alunos, residentes ou não, sem barreiras à relação social com o mundo externo, proibições à saída da unidade ou impedimentos de natureza semelhante. No primeiro semestre de 2015, as Etecs agrícolas ofereciam a residência escolar para 2418 alunos, apesar de possuírem 4380 vagas disponíveis. A taxa de ocupação estava na seguinte relação percentual:

Gráfico 1: Percentual de ocupação da residência escolar do Centro Paula Souza, do total de 4380 vagas disponíveis.

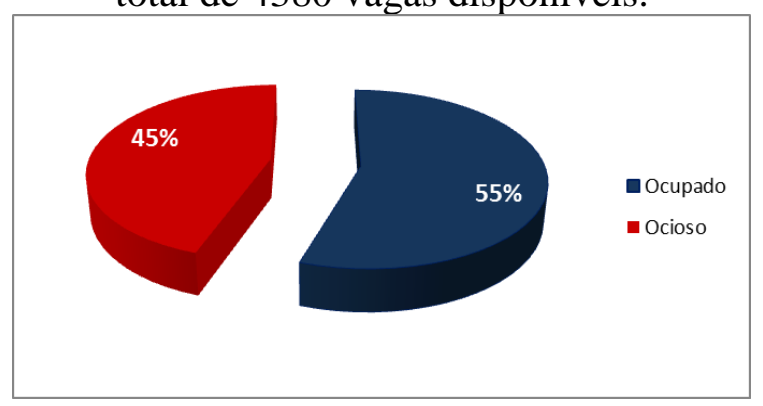

Fonte: Elaboração própria. 
Ao mesmo tempo em que os custos para a manutenção são altos e o sistema é dispendioso de recursos humanos e financeiros para sua gestão adequada, seria importante estimular melhor aproveitamento das vagas disponíveis, pois apenas pouco mais da metade destas encontram-se efetivamente empregadas pelos alunos. Os próprios documentos norteadores nacionais enfatizam o caráter da residência escolar e sua função social, a ser reforçada:

Devido à predominância dessas características na sua demanda, as escolas agrícolas têm tido como peculiaridade o oferecimento de internato para grande parte de seus alunos. O internato, por conseguinte, cumpre uma função social. É útil destacar que, inicialmente esse destinava-se apenas aos meninos. (MEC - SETEC, 2009, p.18).

Atualmente, não apenas o sexo masculino pode acessar o sistema de residência em questão. Dos 2418 alunos residentes nas Etecs agrícolas no primeiro semestre de 2015, meninos e meninas têm usufruído do alojamento nas escolas, apesar de verificarse maior presença dos primeiros, conforme o gráfico demonstra:

Gráfico 2: Proporção de homens e mulheres residentes nas Etecs agrícolas.

Fonte: Elaboração própria.

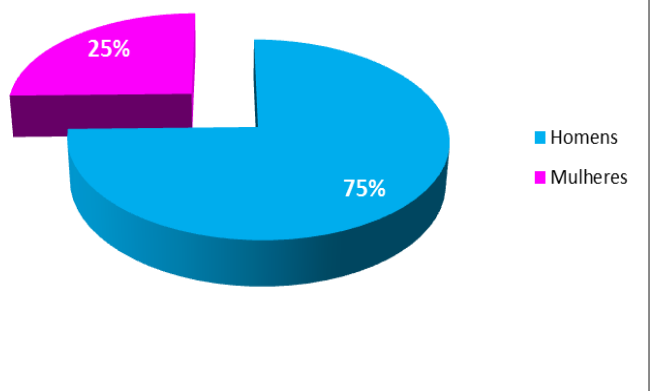

As escolas estudadas constituem um conselho gestor para estes sistemas de residência. $90 \%$ destas unidades possuíam o conselho devidamente eleito e empossado já no início do semestre letivo de 2015. Estes deliberam sobre os investimentos na infraestrutura dos alojamentos, refeições, lazer e nas atividades desenvolvidas na fazenda-escola - em conjunto com os professores e gestores da cooperativa. Para tanto, espera-se que possuam um plano de investimentos e atividades organizado e publicado, conforme analisado no gráfico abaixo: 
Gráfico 3: Proporção de Etecs agrícolas que possuem plano de investimentos para o sistema de residência.

Fonte: Elaboração própria.

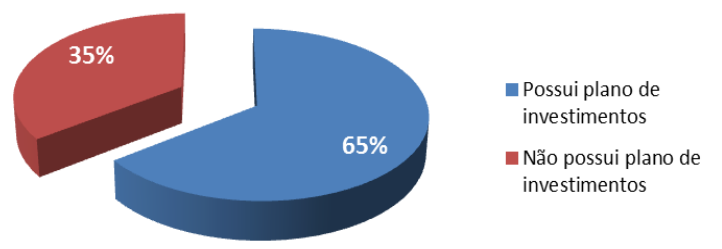

Este planejamento articula-se, muito especialmente, à cooperativa-escola e aos profissionais das Etecs diretamente responsáveis pela manutenção dos sistemas de residência na instituição, o Analista Técnico-Educacional, um cargo concursado; ou o professor responsável pela Orientação Educacional, por meio de projetos realizados com afastamento de parte de suas aulas regulares:

Gráfico 4: Proporção de profissionais das Etecs responsáveis pelo acompanhamento do setor de residência escolar.

Fonte: Elaboração própria.

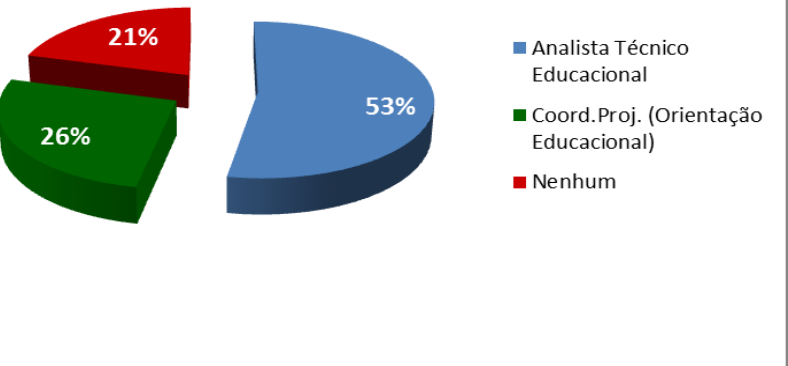

São estes profissionais, em 79\% das escolas, que juntamente às comissões internas compostas pelos próprios alunos cooperados, procuram verificar as condições dos alojamentos, higiene, instalações e alimentação, em uma gestão compartilhada, dos quais se espera uma rotina de verificação e tomada de decisões:

Gráfico 5: Proporção de realização de vistorias periódicas e sistematizadas na residência escolar pelos profissionais das unidades, nas 34 Etecs. 
Fonte: Elaboração própria.

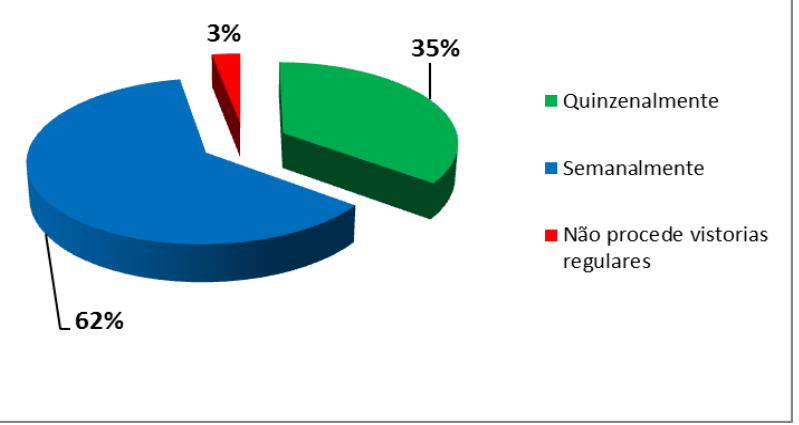

A preocupação com o lazer dos alunos, nos períodos de contra turno escolar e nos finais de semana, é algo relevante para a socialização e o bem-estar dos jovens, especialmente considerando-se que muitos permanecem durante todo o ano ou semestre letivo na escola. O gráfico a seguir demonstra que a maior parte das escolas está mobilizada para este atendimento, com atividades planejadas:

Gráfico 6: Proporção de Etecs que possuem atividades de lazer sistematizadas para os momentos ociosos dos alunos e finais de semana.

Fonte: Elaboração própria.

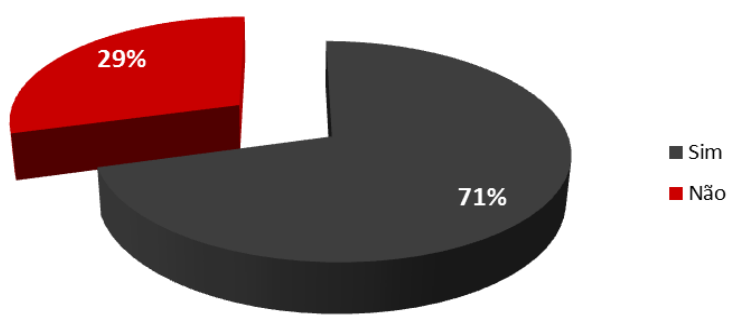

Mesmo nas escolas onde as atividades de lazer não estão organizadas, elas dispõem mais de um recurso aos seus alunos, como campos de futebol, quadra poliesportiva, rede de internet, salas de televisão e jogos, academias, laboratórios de informática com acesso franqueado, anfiteatros e cozinha comunitária. Outras Etecs se organizam para promover aulas de música, capoeira, atividades culturais e esportivas.

A presente pesquisa levantou outros dados que vão desde o perfil dos residentes às condições de uso de internet nas escolas, passando pela higienização dos quartos e banheiros, condições das refeições e do transporte escolar, acessibilidade, uso e compartilhamento dos espaços nos alojamentos. Por questão de escopo do presente 
texto, tais informações não serão debatidas no momento, entretanto, prestam-se ao uso da Administração Central das escolas técnicas do Centro Paula Souza, para fins de gestão dos recursos e aperfeiçoamento das atividades no sistema de residência escolar das Etecs.

\section{Considerações Finais}

Baseados no entendimento dos autores ante os documentos estudados, no levantamento em campo e nas experiências obtidas em anos de trabalho junto às escolas agrícolas, em diferentes funções desempenhadas, como direção de escola, gestão de projetos e supervisão educacional, entendemos que a residência no ensino técnico agrícola contribui para que os estudos acadêmicos ganhem relevância no mundo do trabalho, permitindo que os alunos envolvam-se em atividades pedagógicas e produtivas de acordo com o seu nível de conhecimento, em cada etapa formativa prevista nos planos de curso da instituição. Conforme lembrado por Pologeorgis (2012), os alunos residentes ainda podem ter uma vantagem sobre outros trabalhadores ao encaminharemse ao mercado, pois em sua trajetória escolar contaram com a possibilidade de adquirir habilidades, conhecimentos e atitudes específicos durante seu período de residência, como o profissionalismo, a aplicação de diferentes estilos de liderança e a implantação de variados meios de planejamento e execução do trabalho no campo propriamente dito.

Consideramos que estes alunos residentes também ganham oportunidades de estabelecer contatos com outras pessoas de sua área, o que pode facilitar sua inserção no mercado de trabalho ou a transição de uma área à outra dentro de sua formação. Aumentar a empregabilidade e obter uma formação profissional sólida está entre os objetivos desejáveis desta modalidade de ensino.

Em um momento onde as escolas agrícolas apresentam $72 \%$ do seu alunado ligado originalmente à cidade, e não ao setor rural, o fator residência é considerável como elemento para o envolvimento discente nas atividades de campo. Levar o estudante "a viver a realidade da zona rural" (RUIZ et al, 1985, p.566) por meio da residência torna-se muito importante neste contexto. Além destas particularidades verificadas pela pesquisa, seria preciso considerar que a expansão da oferta e a "melhoria da qualidade da educação no campo exigem ações básicas como a construção e equipamentos [...], a formação dos professores, a aquisição e elaboração de material 
didático específico" (CAVALCANTI et al., 2011, p.6), a facilitação do ingresso dos candidatos nos processos seletivos por meio de avaliações alternativas ao processo 'vestibulinho' presencial, como entrevistas complementares ou avaliação à distância, usando as tecnologias da comunicação e educação disponíveis; a concepção de novos currículos para os cursos do Eixo Recursos Naturais, que pudessem ser desenvolvidos no período noturno, com parte da sua carga horária cumprida aos finais de semana ou em regime de alternância; e o envolvimento dos alunos nas atividades e projetos desenvolvidos pela cooperativa-escola nos diferentes setores produtivos da fazenda, com oportunidades efetivas de estágio extracurricular.

Outro resultado almejado pela proposta é afastar definitivamente do ensino técnico agrícola a forte marca discriminatória que, apesar das mudanças socioeconômicas pelas quais o Brasil passou nos últimos anos, ele ainda carrega: por ser oferecido em escolas localizadas na zona rural, e por muitas delas oferecerem as residências anteriormente reconhecidas como 'internatos', a sociedade por vezes identifica tais escolas como marcadamente assistencialistas e com um caráter direcionado aos "desfavorecidos economicamente" (SOARES; TAVARES, 1999, p. 2223).

Finalmente, partindo destas reflexões, avaliar e revisitar as políticas públicas educacionais, ampliando e fomentando o atendimento da educação profissional no Estado de São Paulo, é outra perspectiva que esta pesquisa espera contemplar, considerando-se que existem vagas ociosas nos sistemas de residência das Etecs e um contingente de alunos que poderiam usufruir destas, ampliando o número de matrículas no ensino médio e técnico público paulista.

\section{Referências}

CAVALCANTI, C.R. et al. Implicações do FUNDEF e do FUNDEB para a educação no campo do Maranhão. In: Anais da V Jornada Internacional de Políticas Públicas. Universidade Federal do Maranhão, 2011. São Luís. p.01-09.

CETEC. Banco de dados do Ensino Técnico no Centro Paula Souza. Disponível em: <http://www.cpscetec.com.br/bdcetec > Acesso em: 30 abr. 2015.

GOFFMAN, E. Manicômios, prisões e conventos. São Paulo: Perspectiva, 1974.

GUARÁ, I. M. R. É imprescindível educar integralmente. Cadernos CENPEC, São Paulo, v. 1, n. 2, p.15-24, 2006. 
PARO, V. H. et al. Escola de tempo integral: desafio para o ensino público. São Paulo: Cortez; São Paulo: Autores Associados, 1988.

POLOGEORGIS, N. The effect of unpaid internships on the work force and the economy. Disponível em:

$<$ http://www.investopedia.com/articles/economics/12/impact-of-unpaid-

internships.asp>. Acesso em: 11 fev.2015.

RUIZ, T. et al. O internato rural do curso de graduação em nutrição da Universidade Federal de Viçosa, Brasil. Revista Saúde Pública, São Paulo, n. 19, p. 566-599, 1985.

SILVA, D. N.; RABINOVICH, E. P. Expectativas parentais: o internato como contexto de desenvolvimento. Revista Brasileira Crescimento Desenvolvimento Humano, n. 17(3), p. 60-71, 2007.

SOARES, A. M. D.; TAVARES, M. G. Formação profissional em ciências agrárias: as transformações no ensino e seus impactos no ensino superior. Revista Educação Agrícola Superior, São Paulo, v. 1, n. 17, jan./jun, p. 18-29, 1999.

SOBRAL, F. J. M. A formação do técnico em agropecuária no contexto da agricultura familiar do oeste catarinense. 2005. Tese, Doutorado em Educação, Campinas: UNICAMP, 2005.

SOBRAL, F. J. M. Retrospectiva histórica do ensino agrícola no Brasil. Revista Brasileira da Educação Profissional e Tecnológica. v.2, n. 2, p. 78-96, Brasília: MEC / SETEC, 2009.

THERRIEN, J; DAMASCENO, M. (Orgs). Educação e escola no campo. Campinas: Papirus, 1993.

TOZONI-REIS, M. F. C. A pesquisa e a produção de conhecimentos. In: UNIVERSIDADE ESTADUAL PAULISTA. Prograd. Caderno de formação: formação de professores - educação, cultura e desenvolvimento. v. 3. São Paulo: Cultura Acadêmica, 2010. p.111-147.

\section{Como referenciar este artigo}

CONSTANTINO, Paulo et al. Residência nas escolas agrícolas de ensino técnico: alternativa para a educação profissional pública no estado de São Paulo. Revista IberoAmericana de Estudos em Educação, Araraquara/SP, v. 12, n. 2, p. 832-844, 2017. Disponível em: <http://dx.doi.org/10.21723/riaee.v12.n2.8392>. E-ISSN: 1982-5587.

Recebido em: 29/02/2017

Aprovação final em: 29/03/2017

RIAEE - Revista Ibero-Americana de Estudos em Educação, v. 12, n. 2, p. 832-844, 2017 